\title{
$\begin{array}{r}\text { WAGENINGEN } \\ \hline\end{array}$
}

Applicability of an innovative steroid-profiling method to determine synthetic growth promoter abuse in cattle

Blokland, M.H.; Tricht, E.F. van; Ginkel L.A. van; Sterk, S.S.

This is a "Post-Print" accepted manuscript, which has been published in "Catena"

This version is distributed under a non-commencial no derivatives Creative Commons (c) (1) () 9 (CC-BY-NC-ND) user license, which permits use, distribution, and reproduction in any medium, provided the original work is properly cited and not used for commercial purposes. Further, the restriction applies that if you remix, transform, or build upon the material, you may not distribute the modified material.

Please cite this publication as follows:

Blokland, M.H.; Tricht, E.F. van; Ginkel L.A. van; Sterk, S.S. (2017) Applicability of an innovative steroid-profiling method to determine synthetic growth promoter abuse in cattle. The J ournal of Steroid Biochemistry and Molecular Biology 174, p. 265-275

You can download the published version at:

https://doi.org/10.1016/j.jsbmb.2017.10.007 


\section{Applicability of an innovative steroid-profiling method to determine synthetic growth promoter abuse in cattle}

M.H. Blokland*, E.F. van Tricht, L.A van Ginkel, S.S. Sterk

RIKILT Wageningen University \& Research, P.O. Box 230, Wageningen, The Netherlands

$10 \quad{ }^{*}$ Corresponding author: M.H. Blokland, Tel.: +31 317 480417, E-mail:

marco.blokland@wur.nl

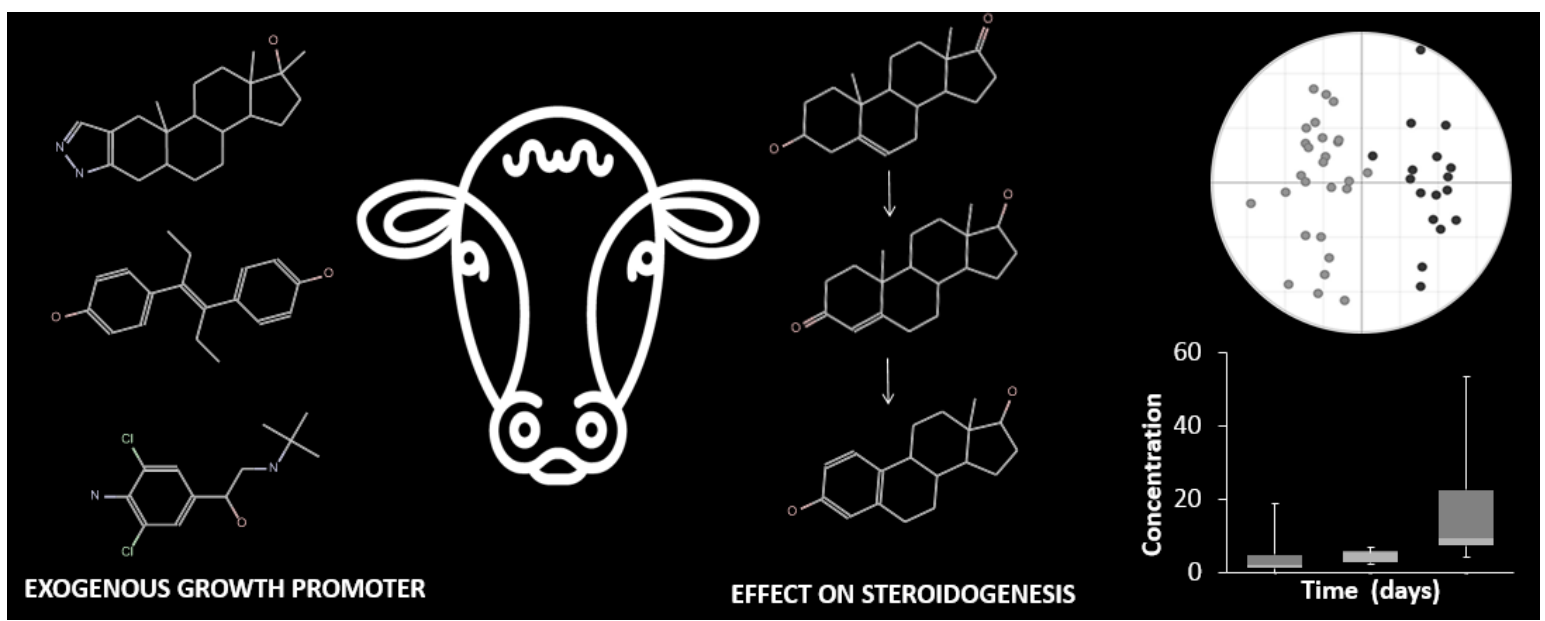

15 Keywords: synthetic steroids, growth promoters, cattle, UHPLC-MS/MS, steroid profiling, steroidogenesis 


\begin{abstract}
20 A robust LC-MS/MS method was developed to quantify a large number of phase I and phase II steroids in urine. The decision limit is for most compounds lower than $1 \mathrm{ng} \mathrm{ml} \mathrm{m}^{-1}$ with a measurement uncertainty smaller than $30 \%$. The method is fully validated and was applied to assess the influence of administered synthetic steroids and beta-agonists on the steroidogenesis. From three animal experiments, clenbuterol, diethylstilbestrol and

25 stanozolol, the steroid profiles in urine of bovine animals were compared before and after treatment. It was demonstrated that the steroid profiles were altered due to these treatments. A predictive multivariate model was built to identify deviations from normal population steroid profiles. The abuse of synthetic steroids can be detected in urine samples from bovine animals using this model. The samples from the animal experiments were randomly analysed

30 using this method and predictive model. It was shown that these samples were predicted correctly in the exogenous steroids group.
\end{abstract}




\section{Introduction}

Due to their anabolic activity, the use of steroids has a long history in enhancing both

35 athlete performance (sports doping) [1, 2] and enhancing growth in cattle during the fattening process (meat production). However, in both sports (fair competition [3]) and meat production (food safety) the use of steroids is prohibited (European Union legislation Directives 96/22/EC, 2003/74/EC and 2008/97/EC [4-6]). These bans [3, 4] on the use of steroids require intelligent control systems.

40 In case a known exogenous steroid is administered, a straightforward targeted approach can be applied to detect this illegal administration just by analyzing samples for the presence of the administrated compound and/or its major metabolite(s) [7]. This approach can be performed by MS/MS measurement, analyzing a set of predefined compounds by product scans, or analysing functional groups covering a broad range of compounds by use

45 of precursor scans. Another approach is by high resolution accurate mass measurement which can analyse a large number of compounds [8]. Also, frequently phase II metabolism is taken into account by measuring metabolites (e.g. glucuronides and sulphates) of the administered compounds [9, 10]. In case of a new unknown (designer) steroid, it is impossible to apply this approach and an alternative untargeted approach is necessary. One

50 possible approach is to use dedicated effect assays to detect the presence of bioactive compounds in samples [11]. After a positive response in such a bioassay, the bioactive compound has to be identified. This approach is known as “effect based screening” and should always be followed by confirmatory targeted analyses for all known candidates. In case such analyses do not result in the detection of the compound responsible for the

55 screening result, a process of identification of the active compound [12] is necessary. 
More recently effect based screening techniques were developed on the basis of steroid profiling $[13,14]$. Steroid profiling has proven to be a versatile technique to pinpoint disruptions in steroidogenesis [15]. These changes can have several causes: e.g. the presence of endocrine disruptors, illness (cancer) or administration of synthetic steroids.

60 Synthetic steroids can be synthetic analogues of endogenous steroids such as testosterone and estradiol. To detect the administration of synthetic analogues of endogenous steroids screening can be performed by steroid profiling $[13,14]$ followed by confirmatory analysis with GC-c-IRMS [16-19]. Exogenous synthetic steroids are compounds like stanozolol, methylboldenone and comparable compounds including designer steroids [20,21] . The

65 mechanism of action following administration of exogenous synthetic steroids lies in the fact that the body will balance its own production of hormones under influence of these administrated steroids. From body-builders it is known that the body will balance or even stops producing steroids [22] when exogenous growth promoters are administered [1]. To investigate whether disruption of steroid profiles also occurs in animals after administration

70 of synthetic growth promoters, we developed a new method based on UHPLC-MS/MS for separating and detecting aglycones, glucuronide- and sulphate- conjugates of steroids in urine.

The purpose was to develop a fast, sensitive and robust method to measure concentrations of all major steroids and metabolites in the steroidogenesis, inclusive of their corresponding

75 glucuronide- and sulphate- conjugates. However, due to their aromatic ring structure and lack of keto groups, detection of estrogenic steroids by LC-MS/MS is hampered by low ionisation efficiency [23]. To overcome this low ionisation efficiency, estrogens can be modified by coupling them with an easily ionisable group [23, 24]. The use of these groups 
enhances the ionisation efficiency [24] by a factor 10 to 100 compared to the original

80 structure and is applied in this study to detect some of the estrogens. The aglycons, glucuronide and sulphate conjugates were effectively isolated and concentrated from samples of urine using a fast generic clean-up based on two different 96 well solid phase extractions (SPE).

In order to further explore steroid profiling as a broad screening method for synthetic

85 growth promoters in bovine animals, it is necessary to further study the influence of different types of compounds on the steroidogenesis. Steroid profiles of animals treated with growth promoters were determined to investigate any change in steroid profiles after treatment. Three treatment regimens were examined: clenbuterol, stanozolol and diethylstilbestrol (DES). Of these compounds, only stanozolol is a steroid hormone. DES

90 was included in this study since it's a hormonal active compound with strong estrogenic activity[25]. Clenbuterol, a $\beta$-agonist, though not a hormonal active compound, was included to test the hypothesis that the use of $\beta$-agonist influences steroidogenesis [26]. These three compounds were used on large scale from the 50s till the end of the 90 s [25, 27] and occasionally are still found nowadays in samples in Europe [12]. The outcome of

95 this study is discussed and evaluated for its applicability in a control strategy to detect synthetic growth promoter abuse in animal husbandry. 


\section{Experimental}

\subsection{Controlled animal treatment experiments}

100 The animal studies were performed following ethical approval at Technical University of Munich, Germany, Wageningen Research, the Netherlands, or the University of Ghent, Belgium. The treatment schemes used were in accordance with the knowledge we have currently on how illegal treatment is conducted.

\subsubsection{Clenbuterol treatment}

The clenbuterol animal experiment was performed by the chair of PhysiologyWeihenstephan of the Technical University of Munich. All animals used in this study were bull calves of 6 to 9 months old, seven animals were used as control group and did not receive any treatment. Seven other animals received orally $10 \mu \mathrm{g} \mathrm{kg}^{-1}$ body weight

110 clenbuterol hydrochloride (clenbuterol) (Boehringer Ingelheim, Ingelheim am Rhein, Germany) each day for 34 days. Urine samples were collected from all animals at day 0, 9, 23, and 34 and were stored at $-20^{\circ} \mathrm{C}$ until analysis.

\subsubsection{Diethylstilbestrol treatment}

115 The diethylstilbestrol animal experiment was performed at the University of Ghent. Six bull calves were randomly selected from a herd of calves. One of the animals was treated twice with 200 mg diethylstilbestrol (DES) orally with a one week interval. From all animals urine was collected five days prior to treatment. These samples are considered as control samples. Urine samples were collected every day during the trial until 8 days after

120 the last dose of DES. Samples were stored at $-20^{\circ} \mathrm{C}$ until analysis. 


\subsubsection{Stanozolol treatment}

The stanozolol animal experiment was performed by the University of Wageningen. Five bull calves were randomly selected. Three were treated with stanozolol. The other two

125 animals served as control animals. The animals were injected four times, with an interval of one week, intramuscularly with $100 \mathrm{mg}$ stanozolol in the neck. The injection site was alternated left and right in the neck. Urine samples were collected one each day for one week prior to the first injection, followed by collection on each day, during three days after each treatment. After the last injection samples were collected each day for one week after

130 which samples were collected for seven weeks, one sample each week. After collection samples were stored at $-20^{\circ} \mathrm{C}$ until analysis.

\subsection{Determination of specific density and total solid content}

Refractometry is a relatively simple method to determine the total amount of solids in urine

135 [28]. Using the specific density of the samples, inter-sample variability in the measured concentration caused by differences in density can be corrected. Correction was performed using the average value 1.020 for the specific gravity of all bovine urine samples used during this study. Concentration $=(1.020-1) /($ Specific Density Sample-1) $\times$ Concentration Sample Samples with a specific density lower than 1.004 were rejected for data-processing, since the

140 correction factors for these samples are too large and the measurement of the specific density is less reliable below 1.004 .

\subsection{Standards}


ß-estradiol, 17 $\alpha$-OH-progesterone, 11-deoxycortisol, 11-deoxycortisol-d5, cortisone, cortisol, cortisol-d4, corticosterone, dehydrocorticosterone, estradiol-3-sulphate, estrone-3-

145 glucuronide, progesterone, testosterone, pregnenolone, estrone-3-sulphate, DHEA-sulphated6 were all obtained from Sigma (the Netherlands). 17 $\alpha-\mathrm{OH}-$ pregnenolone, pregnenoloned4, $5 \alpha$-androstandione, estrone, DHEA, 11-deoxycorticosterone, $\alpha$-testosterone, (5ß,17 $\alpha)$-17hydroxyandrostane-3-one, $(5 \alpha, 17 \alpha)$-17-hydroxyandrostane-3-one, androstandiol- $\alpha, \beta, \beta$, androstandiol- $\beta, \beta, \alpha$, androstandiol- $\alpha, \beta, \alpha$, androstandiol- $-\beta, \beta, \beta$, androstandiol- $\beta, \alpha, \beta$,

150 androstandiol- $\alpha, \alpha, \beta$, androstandiol- $\beta, \alpha, \alpha$, DHEA-sulphate, estradiol-17-sulphate, estrone-17sulphate were obtained from Steraloids (United States). Androsterone-d4, ß-testosterone-d3, 11- (5 $\alpha, 17 ß)-17-h y d r o x y a n d r o s t a n-3-o n e ~(d i h y d r o t e s t o s t e r o n e), ~(5 \alpha, 17 ß)-17-$ hydroxyandrostan-3-one-d3 (dihydrotestosterone-d3), 17ß-testosterone-glucuronide, 17 $\alpha$ testosterone-glucuronide, 17ß-testosterone-sulphate-d3, 17 $\alpha$-testosterone-sulphate, 17ß-

155 testosterone-glucuronide-d3, 17ß-testosterone-sulphate, dihydrotestosterone-sulphate-d3, dihydrotestosterone-sulphate, dihydrotestosterone-glucuronide-d3, androsterone-sulphate-d4, 17 $\alpha$-testosterone-sulphate-d3 were obtained from NMI (Australia). 11-Deoxycorticosteroned8, estrone-d4 and corticosterone-d8 were obtained from CDN Isotopes (Canada). ßestradiol-d3 was obtained from TLC (Canada).Progesterone-2C ${ }^{13}$ was obtained from EURL 160 (Wageningen). Cortisone-d8 was obtained from LGC (the Netherlands). 


\subsection{Materials}

All chemicals and reagents used are of the highest purity grade available (99.9\% pure or higher). Extraction plate manifold, 96-well collection plates (2 ml), Oasis WAX 96-well plate (60 mg sorbent per well, $30 \mu \mathrm{m}$ particle size), Oasis HLB 96-well plate (60 mg sorbent per

170 well, $60 \mu \mathrm{m}$ particle size), 96-Well PTFE/Silicone seal with pre-slit, Acquity UPLC BEH $\mathrm{C}_{18}$ column $(1.7 \mu \mathrm{m}, 2.1 \times 100 \mathrm{~mm})$, Acquity UPLC CSH C 18 column $(1.7 \mu \mathrm{m}, 2.1 \mathrm{x} 100 \mathrm{~mm})$ were purchased from Waters. UPLC-MS/MS system consisting of a Waters ACQUITY UPLC $^{\circledR}$ I-Class System and a Waters triple quadrupole mass spectrometer Xevo TQS with ESI interface. Turbovap evaporator for 96-well plates was purchased from Caliper 175 LifeSciences.

\subsection{Sample preparation method}

To $500 \mu \mathrm{l}$ urine sample or standard, $2 \mu \mathrm{g}^{-1}$ of isotope labelled internal standard mixture (see table 1 for compounds included in the internal standard mixture) is added. A calibration

180 curve is prepared by spiking water with standards (see table 1 for compounds included in the standardmixture) at a concentration of $0,0.5,1.0,2.0,3.0,4.0$ and $10 \mu \mathrm{g} \mathrm{l}^{-1}$. Water is used instead of 'blank urine' because the latter contains endogenous natural hormones which will influence correct quantification. For sample clean-up two types of 96-wells plates were used. First reversed phase to isolate aglycons (Oasis HLB sorbent) was followed by a second plate

185 with a weak anion exchanger to isolate phase II conjugates (Oasis WAX sorbent). The Oasis HLB plate was preconditioned in succession with $500 \mu \mathrm{l}$ of methanol and water and the sample was passed through. The Oasis HLB plate was then washed with $1 \mathrm{ml}$ of water, $1 \mathrm{ml}$ of 55\% methanol/2\% acetic acid and $1 \mathrm{ml}$ of $30 \%$ methanol/2\% ammonia and water, 
respectively. After these washing steps, the relatively polar glucuronides and sulphates are

190 eluted from the HLB plate with 35\% acetonitrile in water and loaded directly to the Oasis WAX plate by stacking the HLB plate onto the WAX plate. The plates are separated and the remaining aglycons are eluted from the HLB plate with acetone and evaporated to complete dryness. A chemical derivatization procedure is carried out to improve measurement sensitivity (see paragraph "Chemical derivatization”). From the extracts $10 \mu \mathrm{l}$ of the mixture

195 is injected directly into the UPLC-MS/MS system. For separation of the aglycons a BEH $\mathrm{C}_{18}$ analytical column is used.

The Oasis WAX plate is washed with $1 \mathrm{ml}$ of water and $1 \mathrm{ml}$ of acetonitrile, respectively. The conjugates are eluted with methanol containing $2 \%$ of ammonia. The eluates are dried and reconstituted in $35 \mu \mathrm{l} \mathrm{10 \%} \mathrm{methanol/water.} 10 \mu \mathrm{l}$ of this solution is injected directly onto

200 the LC-MS/MS. To separate the phase II conjugates, a CSH C 18 analytical column is used.

\subsubsection{Chemical derivatization (aglycon fraction only)}

Picolinic acid reagent is freshly prepared by mixing 50 mg 2-methyl-6-nitrobenzoic anhydride (Sigma-Aldrich), 10 mg 4-dimethylaminopyridin (Sigma-Aldrich), 30 mg

205 picolinic acid (Sigma, P42800), $10 \mathrm{ml}$ THF anhydrous (THF) (Sigma-Aldrich) and $100 \mu \mathrm{l}$ triethylamine (TEA) (Sigma-Aldrich), respectively. To the dried extracts $35 \mu \mathrm{l}$ of the picolinic acid reagent is added. The samples are incubated for 30 minutes at room temperature. THF is evaporated for a few seconds (approximately to half of the original amount) to prevent peak broadening on the UPLC BEH $\mathrm{C}_{18}$ column caused by the presence

210 of organic solvent in the sample. The reaction is stopped by adding $50 \mu \mathrm{l} 5 \% \mathrm{NH}_{3}$ solution. The extract is vortexed and $10 \mu \mathrm{l}$ is directly injected onto the LC-MS/MS system. 
Table 1A. MS/MS conditions and retention time for A) aglycons B) conjugates. The

Quantitative Trace gives the mass-to-charge ratio from the precursor ion and its fragment.

$C E(e V)$ describes the used collision energy. $R T$ describes the retention time. The internal

215 standards are denoted by (IS), PZ: picolinoyl, $\mathrm{Na}^{+}$sodium adduct

\begin{tabular}{|c|c|c|c|c|c|}
\hline $\begin{array}{l}\mathrm{I} \\
\mathrm{D}\end{array}$ & Compound & $\begin{array}{l}\text { Quant. Trace } \\
\text { (MRM) }\end{array}$ & $\begin{array}{l}\mathrm{CE} \\
(\mathrm{eV})\end{array}$ & $\begin{array}{l}\mathrm{RT} \\
(\mathrm{min} .)\end{array}$ & $\begin{array}{l}\text { IS } \\
\text { (ID) }\end{array}$ \\
\hline 1 & Cortisone-d8 (IS) & $369.23>168.09$ & 14 & 1.44 & - \\
\hline 2 & Cortisone & $361.23>163.09$ & 20 & 1.45 & 1 \\
\hline 3 & Cortisol-d4 (IS) & $367.23>121.16$ & 24 & 1.46 & - \\
\hline 4 & Cortisol & $363.17>121.13$ & 25 & 1.47 & 3 \\
\hline 5 & 11-Dehydrocorticosterone & $345.23>121.09$ & 20 & 1.66 & 8 \\
\hline 6 & Corticosterone-d8 (IS) & $355.3>337.35$ & 14 & 1.77 & - \\
\hline 7 & Corticosterone & $347.23>329.22$ & 12 & 1.78 & 8 \\
\hline 8 & 11-Deoxycortisol-d4 (IS) & $352.3>100.2$ & 22 & 1.81 & - \\
\hline 9 & 11-Deoxycortisol & $347.23>97.09$ & 18 & 1.82 & 8 \\
\hline 10 & 11-Deoxycorticosterone-d8 (IS) & $339.3>100.27$ & 18 & 2.18 & - \\
\hline 11 & 11-Deoxycorticosterone & $331.23>97.09$ & 20 & 2.19 & 8 \\
\hline 12 & $\beta$-Testosterone-d3 (IS) & $292.23>109.09$ & 24 & 2.22 & - \\
\hline 13 & $\beta$-Testosterone & $289.23>109.10$ & 22 & 2.23 & 12 \\
\hline 14 & Androstendione-d3 (IS) & $290.20>100.07$ & 20 & 2.26 & - \\
\hline 15 & 4-Androstene-3,17-dione & $287.23>109.09$ & 26 & 2.27 & 14 \\
\hline 16 & $\alpha$-Testosterone & $289.23>97.10$ & 22 & 2.34 & 12 \\
\hline 17 & $17 \alpha$-OH-Progesterone & $331.23>97.09$ & 24 & 2.34 & 14 \\
\hline 18 & $5 \alpha$-Androstanedione & $289.20>213.18$ & 18 & 2.59 & 14 \\
\hline 19 & $\beta$-Estradiol-d3-PZ (IS) & $381.2>159.1$ & 10 & 2.70 & - \\
\hline 20 & $\beta$-Estradiol-PZ & $378.2>124.1$ & 22 & 2.71 & 19 \\
\hline 21 & Progesterone-2C13 (IS) & $317.17>99.13$ & 20 & 2.84 & - \\
\hline 22 & Progesterone & $315.23>109.18$ & 24 & 2.85 & 21 \\
\hline 23 & $17 \alpha-\mathrm{OH}$-Pregnenolone (M-H2O) & $315.3>297.21$ & 12 & 3.10 & 21 \\
\hline 24 & DHEA-PZ Na ${ }^{+}$ & $416.17>146.07$ & 16 & 3.13 & 14 \\
\hline 25 & Etiocholanolone-PZ Androsterone-PZ & $396.17>124.07$ & 12 & 3.18 & 26 \\
\hline 26 & Androsterone-d4-PZ (IS) & $400.23>124.92$ & 14 & 3.21 & - \\
\hline 27 & $(5 \alpha, 17 \beta)-17$-hydroxyandrostane-3-one-d3-PZ (IS) & $399.2>124.1$ & 12 & 3.21 & - \\
\hline 28 & $\begin{array}{l}(5 \alpha, 17 \beta)-17-h y d r o x y a n d r o s t a n e-3-o n e-P Z \text { (=DHT- } \\
\text { PZ) }\end{array}$ & $396.17>255.17$ & 16 & 3.22 & 27 \\
\hline 29 & $(5 \alpha, 17 \alpha)$-17-hydroxyandrostane-3-one-PZ & $396.17>255.17$ & 16 & 3.29 & 27 \\
\hline 30 & $(5 \beta, 17 \alpha)$-17-hydroxyandrostane-3-one-PZ & $396.17>124.07$ & 12 & 3.34 & 27 \\
\hline
\end{tabular}




\begin{tabular}{|l|l|l|r|r|r|}
31 & Pregnenolone-d4-PZ Na & & \\
& (IS) & $448.3>146.13$ & 16 & 3.59 & - \\
\hline 33 & Pregnenolone-PZ Na & $444.26>146.08$ & 16 & 3.60 & 27 \\
\hline
\end{tabular}

Table 1B. MS/MS Conditions for analysis of conjugates ( $G=$ glucuronide, $S=$ sulphate)

\begin{tabular}{|c|c|c|c|c|c|}
\hline ID & Compound & Quant. Trace (MRM) & CE (V) & RT (min.) & IS (ID) \\
\hline 1 & Estriol-17-G & $463.17>287.51$ & 28 & 1.20 & 7 \\
\hline 2 & $\beta$-Estradiol-3-G & $447.23>271.11$ & 30 & 1.55 & 7 \\
\hline 3 & $\beta$-Estradiol-17-G & $447.23>271.11$ & 30 & 1.74 & 7 \\
\hline 4 & Estrone-3-G & $445.17>113.05$ & 18 & 1.78 & 7 \\
\hline 5 & $11 \beta$-OH-Androsterone-G & $481.23>85.05$ & 30 & 1.86 & 7 \\
\hline 6 & Hydroxyprogesterone-11G & $505.23>113.01$ & 28 & 1.99 & 7 \\
\hline 7 & 17ß-Testosterone-G-d3 (IS) & $468.3>97.12$ & 28 & 2.00 & - \\
\hline 8 & $17 \beta$-Testosterone-G & $465.23>97.12$ & 28 & 2.01 & 7 \\
\hline 9 & $5 \alpha$-Androstanediol-3 $\beta, 17 \beta-3 G$ & $467.23>113.01$ & 30 & 2.03 & 7 \\
\hline 10 & Dihydroxyprogesterone-G & $507.23>113.01$ & 30 & 2.03 & 7 \\
\hline 11 & DHEA-3-G & $463.23>75.04$ & 28 & 2.22 & 7 \\
\hline 12 & Estradiol-3-S & $351.1>80.09$ & 26 & 2.49 & 7 \\
\hline 13 & Estrone-3-S & $349.1>269.07$ & 30 & 2.49 & 7 \\
\hline 14 & Dihydrotestosterone-G-d3 (IS) & $468.23>112.98$ & 26 & 2.53 & - \\
\hline 15 & Dihydrotestosterone-G & $465.2>113$ & 26 & 2.54 & 14 \\
\hline 16 & $17 \beta$-Testosterone-S-d3 (IS) & $370.1>97.96$ & 30 & 2.97 & - \\
\hline 17 & $17 \beta$-Testosterone-S & $367.1>96.99$ & 30 & 3.01 & 16 \\
\hline 18 & Etiocholanolone-G & $465.2>113$ & 30 & 3.07 & 20 \\
\hline 19 & Estrone-17-S & $349.1>269.07$ & 30 & 3.07 & 16 \\
\hline 20 & Androsterone-G-d4 (IS) & $469.23>85.05$ & 30 & 3.17 & - \\
\hline 21 & $17 \alpha$-Testosterone-S-d3 (IS) & $370.1>97.96$ & 30 & 3.20 & - \\
\hline 22 & $17 \alpha$-Testosterone-S & $367.1>96.99$ & 30 & 3.25 & 21 \\
\hline 23 & Pregnenolone-G & $491.23>113.01$ & 28 & 3.34 & 31 \\
\hline 24 & DHEA-S-d6 & $373.17>97.93$ & 30 & 3.44 & - \\
\hline 25 & DHEA-S & $367.1>96.99$ & 30 & 3.48 & 24 \\
\hline 26 & DHT-17-S-d3 (IS) & $372.17>97.96$ & 30 & 3.50 & - \\
\hline 27 & DHT-S & $369.17>96.99$ & 30 & 3.55 & 26 \\
\hline 28 & Androsterone-S-d4 (IS) & $373.17>97.9$ & 30 & 3.66 & - \\
\hline 29 & $5 \alpha$-Androstane-3b-ol-17-one-S-d2 (IS) & $371.17>96.99$ & 30 & 3.66 & 28 \\
\hline 30 & $5 \alpha$-Androstane-3b-ol-16-one-S + Epi-Androsterone-S & $369.1>96.99$ & 30 & 3.70 & 28 \\
\hline 31 & Pregnenolone-S-d4 (IS) & $399.17>96.99$ & 30 & 3.81 & - \\
\hline 32 & Androsterone-S + Etiocholanolone-S & $369.17>96.99$ & 30 & 3.93 & 28 \\
\hline 33 & Pregnenolone-S & $395.17>96.99$ & 28 & 4.29 & 31 \\
\hline
\end{tabular}




\subsection{LC-MS/MS analysis}

\subsubsection{Conditions for UPLC-MS/MS analysis of aglycons}

Chromatographic separation of aglycons is performed on a Waters Acquity UPLC BEH $\mathrm{C}_{18}$, $1.7 \mu \mathrm{m}, 2.1 \mathrm{x} 100 \mathrm{~mm}$. The flow rate is $0.6 \mathrm{ml} \mathrm{min}^{-1}$ at a column temperature of $80^{\circ} \mathrm{C}$. The LC mobile phase consists of solution A (10\% acetonitrile/0.1\% formic acid in water) and solution B (90\% acetonitrile/0.1\% formic acid in water). Aglycon compounds were eluted

225 according to the following gradient: 0-0.2 $\mathrm{min} .5 \% \mathrm{~B}$; 0.2-0.5 $\mathrm{min}$. 20\%B; 0.5-3.5 min. 80\%B; 3.5-3.6 min. 95\%B; 3.6-4.05 min. 95\%B; 4.05-4.1 min. 5\%B. The gradient was linear. From the aglycon sample $10 \mu \mathrm{l}$ is injected (partial loop with needle overfill and load ahead).

$230 \quad$ 2.6.2 Conditions for UPLC-MS/MS analysis of conjugates Chromatographic separation of conjugates is performed on a Waters Acquity UPLC CSH $\mathrm{C}_{18}, 1.7 \mu \mathrm{m}, 2.1 \times 100 \mathrm{~mm}$. Flow rate $0.6 \mathrm{ml} / \mathrm{min}$ with a column temperature of $80^{\circ} \mathrm{C}$. The LC mobile phase consists of solution A (10\% acetonitrile/0.1\% formic acid in water) and solution B (90\% acetonitrile/0.1\% formic acid in water). Conjugated compounds are eluted

235 according to the following gradient: 0-0.3 min. 5\%B; 0.3-0.4 min. 20\%B; 0.4-3.0 min. 35\%B; 3.0-3.1 min. 99\%B; 3.1-6.0 min. 99\%B; 6-6.1 min. 5\%B. From the conjugate sample $10 \mu \mathrm{l}$ is injected (partial loop with needle overfill and load ahead).

\subsubsection{Settings and conditions for MS/MS analysis of aglycons and conjugates}

240 The MS system switches between positive and negative ion ionisation during analysis. The capillary voltage was set to $3.0 \mathrm{kV}$, the cone voltage was adjusted to $40 \mathrm{~V}$, cone gas 150 litres 
per hour. The source temperature was $150^{\circ} \mathrm{C}$ and the desolvation temperature was $590^{\circ} \mathrm{C}$. The flow of the desolvation gas is 1000 litres per hour. The LM 1 Resolution is 2.8 and the HM Resolution is 14.5. The Ion Energy 1 is set to 0.6 and the Ion Energy 2 to 0.8 . In table 1

245 an overview is given of the transitions measured for each compound included.

\subsection{Data processing}

LC-MS/MS data was automatically processed using MassLynx V4.1 software from Waters. All peak integrations were manually checked and baseline corrected if necessary. To correct

250 for recovery losses during sample clean-up the internal standards as denoted in table 1 were used. Concentrations below CC $\alpha$ were rejected and not used for further statistical evaluation of the results.

\subsubsection{Multivariate analysis}

255 Quantitative concentrations of steroids and their conjugates were measured, followed by a standardized multi-variate analysis. Part of the workflow is identification of the compounds that are influenced by administration of exogenous growth promoters.

The quantitative measurement results are exported from QuanLynx software and imported to MS Excel. This excel sheet is imported into Simca13 (Umetrics). Outliers in the Principal

260 component analysis (PCA) plots are detected by using the Hotelling's T2 and DModX function. The SIMCA (Soft Independent Modelling of Class Analogy) software requires that the size of the blank observations group is reduced to about the same size as the treatment group. If the groups are not balanced in number the model is 'warped'[29]. This reduction 
takes place through random selection. The data is $\log 10$ transformed and Pareto scaled. The

265 probability of all the statistics used is 0.95.

For determination of the compounds responsible for the separation of the treated and not treated animals is orthogonal partial least square discriminant analysis (OPLS-DA) used. Control and cross-validation of the OPLS-DA models is performed by means of the so called 'Summary of Fit plot', whereby the R2 (descriptive factor) and the Q2 value (predictive 270 factor) are determined.

Validation of the OPLS-DA model is implemented through a permutation test of the OPLSDA model. A permutation test randomly swaps the identity of samples and remodels the data. Permutation test on a good model gives less good R2 and Q2 values on random permutation. These values should always be lower than the original values.

275 To determine the difference between steroid profiles of treated and non-treated animals a list of compounds that affect the separation of the groups in the OPLS-DA model mostly was determined by means of an S-plot. The variables were identified by selection of the compounds that were projected in the upper right and lower left of the S-plot.

\subsection{Validation of the method for urine}

Validation of the analytical method was performed for all compounds in Table 1. For these compounds the $\mathrm{CC} \alpha, \mathrm{CC} \beta$ and measurement uncertainty were determined. The decision limit (CC $\alpha$ ) and detection capability (CCß) [30] were determined using a three point standard calibration curve in different blank urine samples. Each sample spiked at the same

285 concentration was fully processed in six-fold on each day as if it was an unknown sample. This set of samples was analysed on three different days. From this calibration curve the y- 
intercept and slope were calculated $(\mathrm{y}=\mathrm{ax}+\mathrm{b})$. The CC $\alpha$ and CCß were calculated according to ISO11843 [31] .4 The (within day) repeatability and within laboratory reproducibility (between days) were determined from the obtained dataset using the approach as described

290 in ISO 5725 [32]. The measurement uncertainty was calculated by the square root of the summation of the squares of the relative standard deviations of each validation level divided by three. 


\section{Results and Discussion}

\subsection{Method development}

Not all steroids can be ionized using electrospray [23]. For example, all estrogenic compounds have to be derivatized with easily ionisable groups to enable ionization by electrospray [23]. To enhance the ionisation picolinic acid derivatization [23, 24] was implemented. The estradiol picolinoyl derivative has a very intense signal (figure 1B) in comparison with the aglycon. The coupling reaction of 17ß-estradiol is depicted in Figure 1A. Figure $1 \mathrm{~B}$ shows the extracted trace of a standard of $10 \mathrm{pg}$ of estradiol coupled to picolinic acid and its corresponding MS/MS spectra (figure 1C).

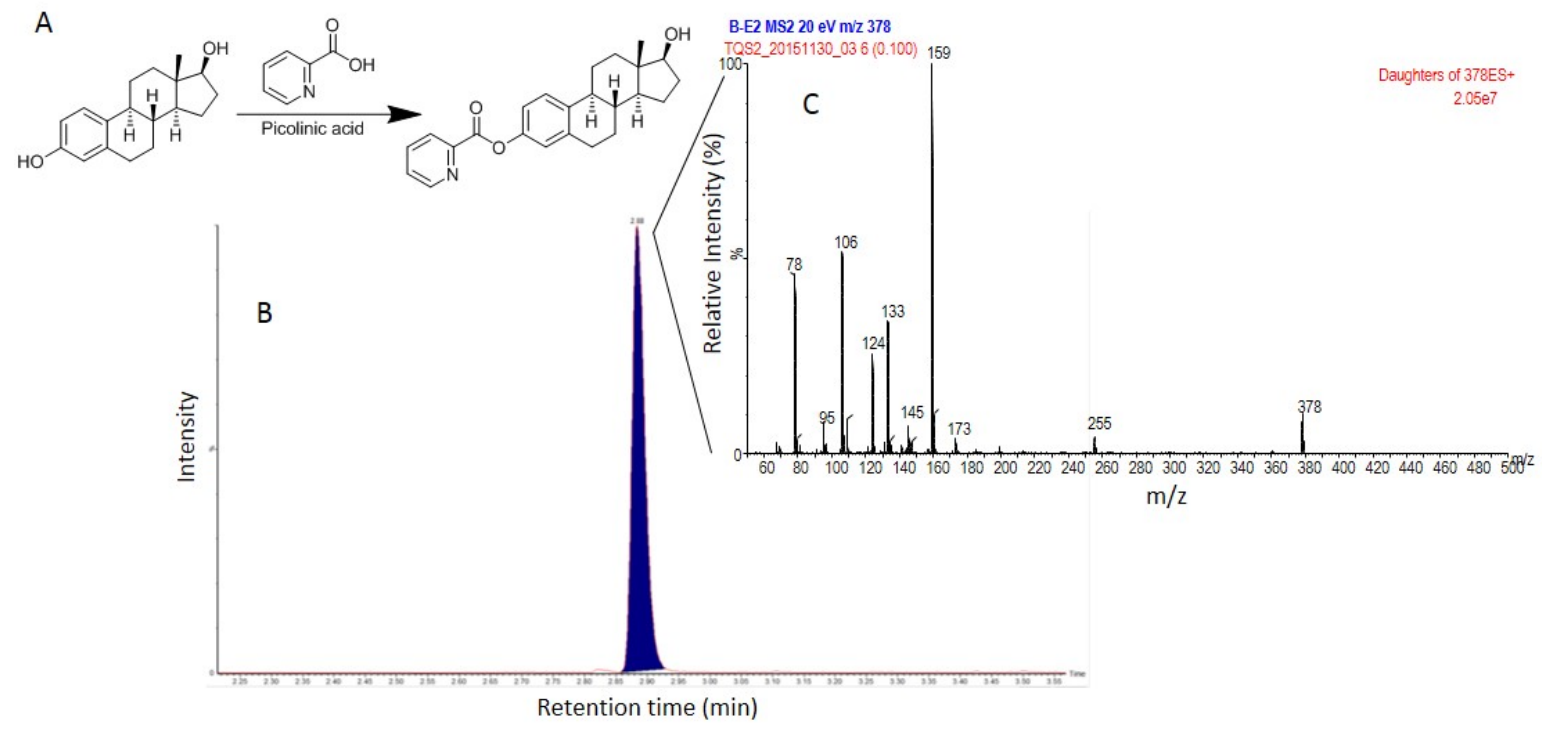

Figure 1. A) Coupling reaction of picolinic acid with 17ß-estradiol on the 3-position.

305 B) Extracted ion chromatogram of transition 378.2>124.1 of a standard of $10 \mathrm{pg}$ estradiol picolinoyl. C) corresponding product spectra of $\mathrm{m} / \mathrm{z} 378.2$ by a collision energy of $20 \mathrm{eV}$.

To investigate the stability of estradiol-picolinic acid, a batch of standards containing $0.1 \mathrm{ng}$ $\mathrm{ml}^{-1}$ estradiol picolinoyl derivative was prepared and injected at fixed time intervals for 24 hours on the MS. The stability of the MS during this experiment was checked with non- 
coupled standards. After 24 hours, the signal was 86 percent of the original signal, and therefore considered as stable.

\subsection{Pre-validation: ruggedness of developed method}

315 Due to the presence of endogenous steroids, it is difficult to evaluate the performance of the method by means of spiking these steroids. Therefore, a pre-validation was performed to assess the ruggedness of the method prior to a full method validation. As the isotope labelled internal standard mixture are not endogenous, a clear first indication of ruggedness, recovery and possible signal suppression of the method is obtained. For this, in

320 a 96 well-plate, 96 different bovine urines were spiked with the internal standard mixture, and recovery for this internal standard mixture was calculated. In figure 2 the recovery of isotope labelled testosterone; the free compound and the phase II metabolites are plotted, also the average recoveries and the relative standard deviations are shown. 

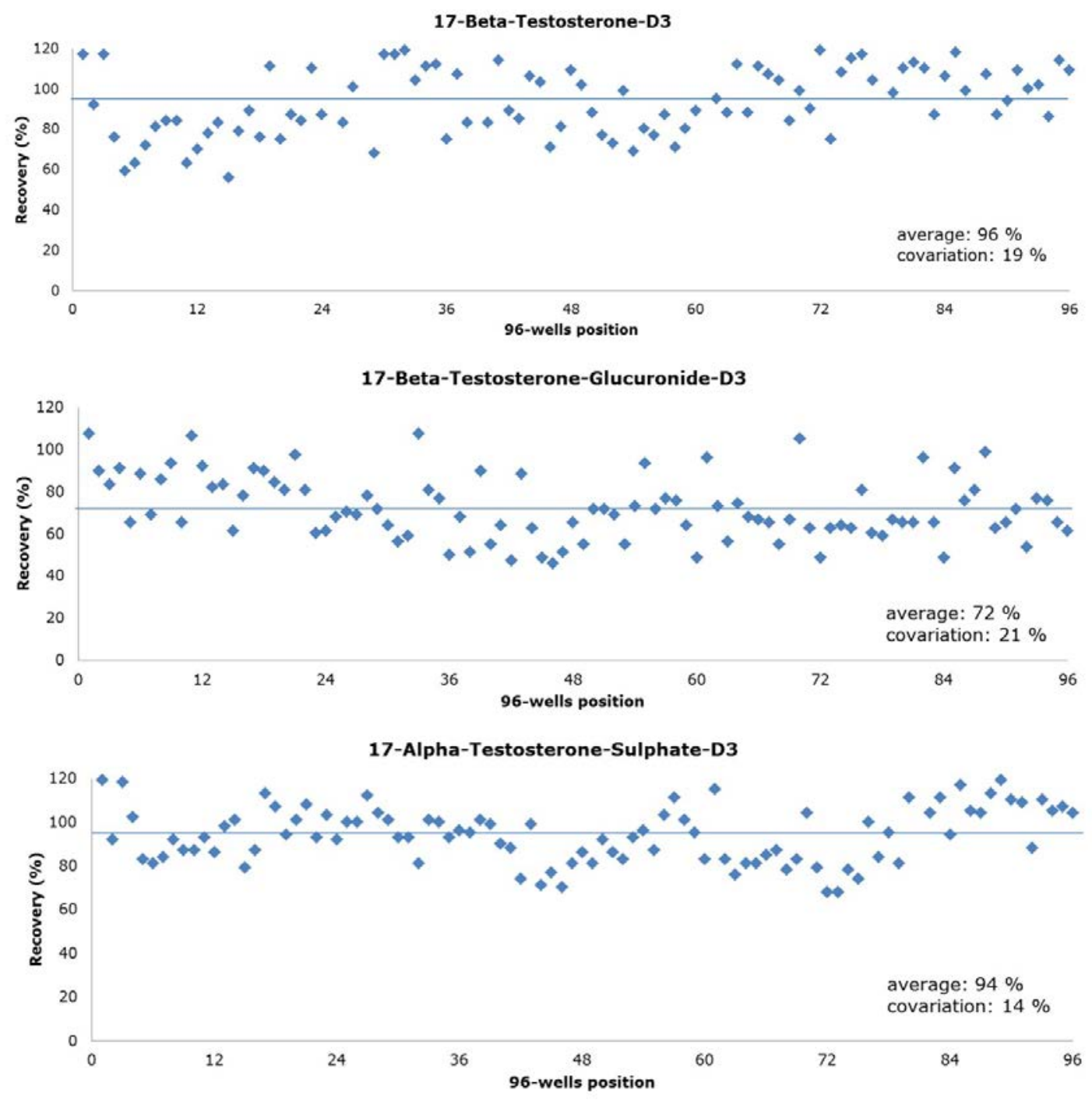

Figure 2. Recovery of 96 different bovine urine samples spiked at $2 \mathrm{ng} \mathrm{ml}^{-1}$ isotope labelled internal standard mix for; A) 17ß-testosterone-D3. B) 17ß-testosterone-glucuronide-D3. C) $17 \alpha$ testosterone-sulphate-D3.

For 17ß-testosterone-D3 an average recovery of $96 \%$, with a relative standard deviation of 19\% was obtained. However, for 17ß-testosterone-glucuronide-D3 a lower recovery of 72\% with a slightly higher relative standard deviation of $21 \%$, was found. This can be explained by the fact the glucuronides are not strongly bound to the weak anion exchange 
340 material and partly elute with the washing solvents. The opposite happens for $17 \alpha-$ testosterone-sulphate-D3 where the sulphate groups bind much stronger than a glucuronide group to a weak anion exchange material. This is reflected in the higher recovery of $94 \%$ and lower relative standard deviation of $14 \%$. Nevertheless, for all three compounds , recovery and relative standard deviation were considered adequate for residue analysis at

345 low ng ml ${ }^{-1}$ levels, especially when it is considered that these are not recovery corrected concentrations. Although the recovery is considered as adequate the concentrations of steroids determined in this study were corrected using the internal standards to obtain a more precise quantification since e.g. sample specific ion-suppression is taken into account.

\section{$350 \quad 3.3$ Method validation}

In a previous study [14] the $95 \%$ confidence interval of the concentration of natural hormones were determined for all natural hormones, the determined concentration was between $0.2-2 \mathrm{ng} \mathrm{ml}^{-1}$ for the free and the phase II conjugates. The validation concentration levels were chosen to cover this concentration range. To validate a method for natural

355 hormones in urine the urine has to be pre-treated to remove endogenous natural hormones since the concentration levels of natural hormones will fluctuate from sample to sample. These fluctuating concentrations will influence the outcome of the validation study. To diminish these influences the urine was stripped of its natural hormones by treating the urine with activated charcoal. Analyses of stripped urine confirmed that all natural

360 hormones were removed. Spiking the stripped urine with natural hormones and phase II metabolites followed by the full validation gives a true reflection of the performance of the method in combination with the results of the pre-validation. The method was validated 
according to the guidelines set in Commission Decision 2002/657 [30]. All compounds of interest were analysed within 5 minutes and are mostly separated. In the supplementary

365 data an example chromatogram is shown for urine spiked at $0.1 \mathrm{ng} \mathrm{ml}^{-1}$.

In table 2 an overview is given of the validation results. The results of the validation confirm that LC-MS/MS measurement of a large group of (pro)hormones is possible with acceptable performance charateristics. For all natural steroids measured the CC $\alpha$ for most aglycons in the range of 0.1-0.79 $\mathrm{ng} \mathrm{ml}^{-1}$ which is in the expected concentration range of

370 natural hormones. The CC $\alpha$ values for pregnenolone-picolinoyl as sodium adduct and the $5 \alpha$-androstanedione and DHEA-picolinoyl sodium adduct are in the range $1.2-2.9 \mathrm{ng} \mathrm{ml}^{-1}$ which is not in the $95 \%$ confidence concentration level of a normal population, this will limit the use of this method for these compounds. The measurement uncertainty for most compounds is lower than $30 \%$. This higher variability can be due to the fact that sodium

375 adducts are measured which is not the preferred choice for a protonated molecule. In this case no other options were available. The accuracy for all compounds is within the range of 92-133\% which is considered as acceptable for the intended use of this method.

The performance of the method for the glucuronide- and the sulphate- conjugates is comparable with the performance for aglycons. The $\mathrm{CC} \alpha$ values are between $0.1-1.9 \mathrm{ng}$

$380 \mathrm{ml}^{-1}$ and the measurement uncertainties between $4-71 \%$. These values are a bit higher than for the aglycons. This is probably due to the two SPE steps involved in the extraction. Although higher, they are considered acceptable as they fall in the 95\% confidence limit of natural compounds. The accuracy is between $80-120 \%$. So overall the performance is adequate and suitable for the intended use and can quantify natural hormones at 385 endogenous levels. When the performance of the method is compared to recently published 
Table 2A. Performance characteristics for the aglycons, the CC $\alpha$ and $C C \beta$ are in $\mathrm{ng} \mathrm{ml}^{-1}$, the measurement uncertainty (MU) in \% and the accuracy (acc) in \%

\begin{tabular}{|c|c|c|c|c|}
\hline Aglycons & $\mathrm{CCa}$ & $\overline{C C \beta}$ & MU & Acc \\
\hline Cortisone & 0.91 & 1.82 & 25.1 & 100.7 \\
\hline Cortisol & 0.53 & 1.06 & 16.9 & 99.5 \\
\hline 11-Deoxycorticosterone & 0.42 & 0.84 & 14.6 & 104.3 \\
\hline Corticosterone & 0.54 & 1.09 & 16.7 & 104 \\
\hline 11-Deoxycortisol & 0.33 & 0.65 & 11.2 & 99.9 \\
\hline 11-Dehydrocorticosterone & 0.72 & 1.45 & 36.4 & 108.9 \\
\hline$\beta$-Testosterone & 0.43 & 0.86 & 16.9 & 108.1 \\
\hline 4-Androsten-3,17-dione & 0.7 & 1.41 & 22.3 & 96.9 \\
\hline$\alpha$-Testosterone & 0.85 & 1.71 & 22.6 & 104 \\
\hline $17 \alpha$-OH-Progesterone & 0.54 & 1.08 & 19.6 & 93.5 \\
\hline $5 \alpha$-Androstanedione & 1.22 & 2.43 & 54.7 & 101.9 \\
\hline$\beta$-Estradiol & 0.41 & 0.82 & 15.6 & 105.3 \\
\hline Progesterone & 0.33 & 0.66 & 20.6 & 101.7 \\
\hline Pregnenolone & 2.99 & 5.97 & 116.2 & 98.7 \\
\hline DHEA & 1.69 & 3.37 & 73.2 & 132.9 \\
\hline Etiocholanolone and Androsterone & 0.71 & 1.41 & 26.8 & 103.7 \\
\hline$(5 \alpha, 17 \beta)$-17-hydroxyandrostan-3-one & 0.54 & 1.09 & 29.8 & 114.3 \\
\hline$(5 \alpha, 17 \alpha)$-17-hydroxyandrostan-3-one & 0.52 & 1.04 & 55.7 & 118.9 \\
\hline$(5 \beta, 17 \alpha)$-17-hydroxyandrostan-3-one & 0.53 & 1.07 & 27.8 & 113.1 \\
\hline 17 $\alpha$-OH-Pregnenolone & 2.72 & 3.45 & 48.7 & 107.1 \\
\hline
\end{tabular}


Table 2B. Performance characteristics for the glucuronide and the sulphate conjugates, the $C C \alpha$ and $C C \beta$ are in $\mathrm{ng} \mathrm{ml}^{-1}$, the measurement uncertainty (MU) in \% and the accuracy (acc) in \%, G=glucuronide, $S=$ sulphate

\begin{tabular}{|c|c|c|c|c|}
\hline Conjugates & $\mathrm{CC \alpha}$ & $\mathbf{C C \beta}$ & MU & Acc \\
\hline Estriol-17-G & 0.88 & 1.75 & 33.5 & 95.4 \\
\hline$\beta$-Estradiol-3-G & 0.38 & 0.76 & 14.1 & 100.3 \\
\hline$\beta$-Estradiol-17-G & 0.5 & 1 & 29 & 100.9 \\
\hline Estrone-3-G & 0.31 & 0.62 & 16.3 & 101.2 \\
\hline $11 \beta$-OH-Androsterone-G & 1.72 & 3.44 & 58.2 & 79.4 \\
\hline Hydroxyprogesterone-11G & 0.95 & 1.9 & 60.8 & 99.7 \\
\hline Estradiol-3-S & 0.15 & 0.3 & 10.2 & 98.7 \\
\hline $17 \beta$-Testosterone-G & 0.38 & 0.77 & 27.8 & 108.1 \\
\hline $5 \alpha$-Androstanediol-3 $3,17 \beta-3 G$ & 0.61 & 1.22 & 51 & 118.2 \\
\hline Dihydroxyprogesterone-G & 1.49 & 2.98 & 49.4 & 102.2 \\
\hline $17 \beta$-Testosterone-S & 0.35 & 0.71 & 30.5 & 104.1 \\
\hline Etiocholanolone-G & 0.49 & 0.97 & 19.7 & 102.2 \\
\hline Estrone-17-S & 0.19 & 0.39 & 11.6 & 98.4 \\
\hline $17 \alpha$-Testosterone-S & 0.2 & 0.4 & 6.9 & 103 \\
\hline Pregnenolone-G & 1.82 & 3.65 & 71.3 & 80.9 \\
\hline DHEA-S & 0.1 & 0.21 & 4.3 & 100.3 \\
\hline DHT-S & 0.65 & 1.3 & 23.8 & 100.5 \\
\hline $\begin{array}{l}5 \alpha \text {-Androstane-3 } \beta \text {-ol-16-one-S and Epi- } \\
\text { Androsterone-S }\end{array}$ & 0.21 & 0.43 & 13.1 & 103.5 \\
\hline Androsterone-S + Etiocholanolone-S & 0.16 & 0.31 & 7.4 & 102.7 \\
\hline Pregnenolone-S & 0.12 & 0.25 & 5.8 & 101.9 \\
\hline
\end{tabular}


400 methods, this method is the only fully validated method described which simultaneously measure aglycons and conjugates in urine. Some of the published methods are not validated and are published as proof of principle [13, 33] or are applied to different matrices [34-36].

\subsection{Effect of exogenous compounds on steroid profiles}

405 For each treatment type (see experimental sections), the steroid profiles were analysed of all animals involved. The steroid profiles of the control population (samples from the nontreated animals or taken before treatment) were compared with the treated population. To identify the steroids that are up or down regulated between the two populations an OPSL-DA analysis was performed for all three treatments, e.g clenbuterol, diethylstilbestrol and

410 stanozolol. The graphical representation of the OPLS-DA analysis is shown in figure 3. 

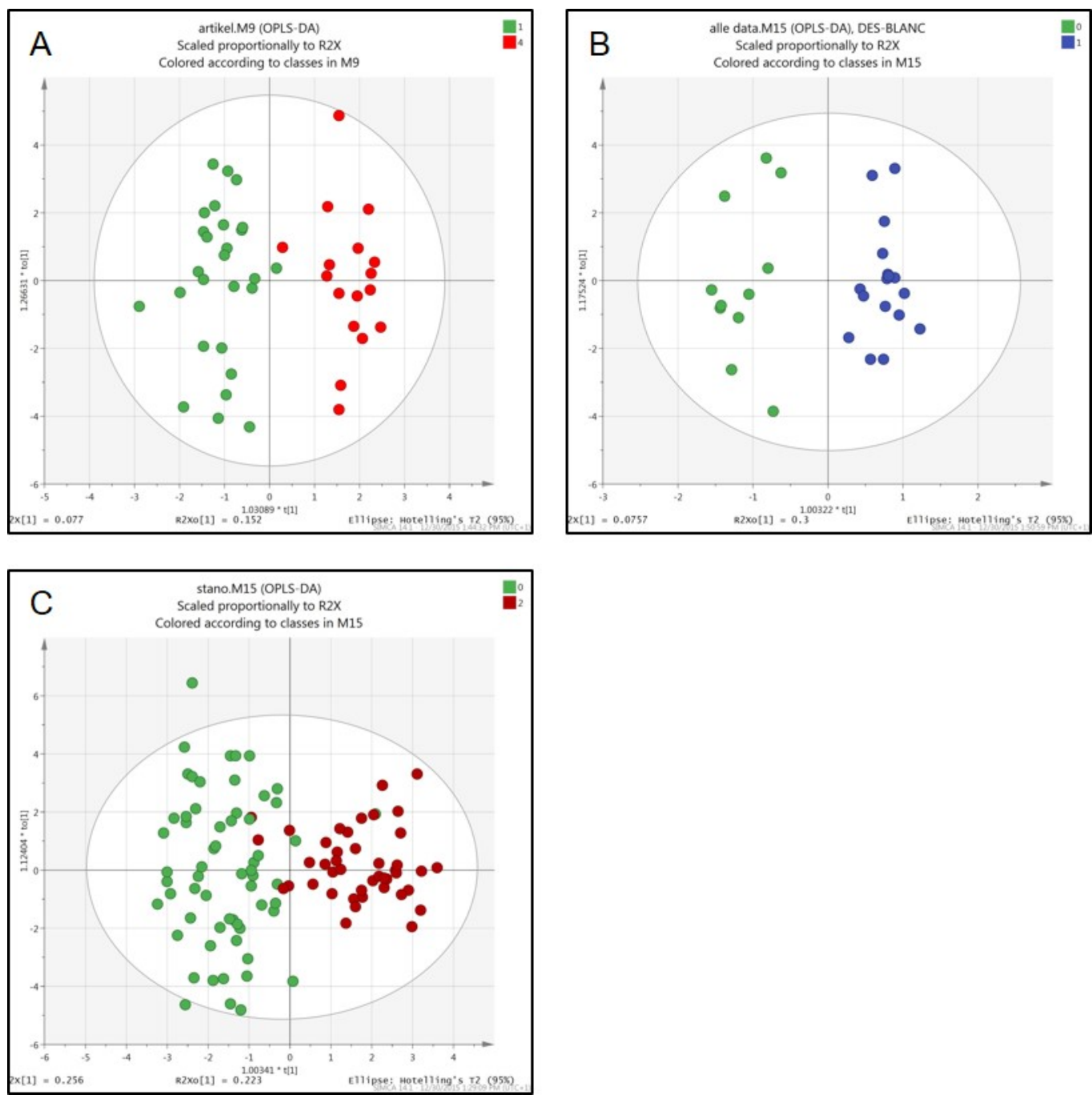

420 Figure 3. A) OPLS-DA plots for the three different types of treatments, A) Clenbuterol - non-treated (green) vs the treated (red) population. B) DES - non-treated (green) vs the treated (red) population C) stanozolol - non-treated (green) vs the treated (red) population.

As is depicted in figure, there is a clear separation for all three treatments between the treated 425 and non-treated animals. The R2 (measurement of fit) and Q2 (prediction of the model according to cross validation) were higher for all three treatments than $>0.7$ and $>0.5$, respectively. These values are greater than 0.5 which is considered as a good indication of a robust model [37]. The OPLS-DA permutation test furthermore shows that the model is 
robust. The corresponding S-Plot from the OPLS-DA shows the compounds that contribute

430 most to the separation of the groups. These compounds were further evaluated for their contribution to the separation.Clenbuterol administration

The concentrations of clenbuterol remained stable during the treatment period, see for the excretion curves in supplementary data. Estradiol-17ß-glucuronide and estrone-3-glucuronide are down regulated after treatment with clenbuterol. For other compounds no up- and or 435 down-regulation was observed, the concentrations remained constant during the trail and between the groups. The distribution of the measured concentrations of each compound related to treatment time are plotted in a Box-Whisker plot (figure 4).

It was not expected to see such a decrease in the production of estradiol-17 $\beta$-glucuronide and estrone-3-glucuronide. To the best of our knowledge these effects are not described in

440 literature before. However, there are some indications in literature that there is an effect of clenbuterol treatment on the estrogenic receptors. In one study the up-regulation of estrogen and progesterone receptors in the reproductive system of female veal calves were induced by clenbuterol administration (13). The mechanism causing up-regulation of receptors is not known, but it is known that there is a direct correlation between the concentration of estradiol 445 and the number of receptors. Maybe these effects are correlated and caused by the clenbuterol treatment. Unfortunately, not enough data is available in literature to verify this. Another study indicates that clenbuterol affects the synthesis of estrogens (14). In this study steroid profiles of 22 postmenopausal asthmatic women using beta-agonists and 22 agematched, postmenopausal, nonasthmatic women were compared. A significant decrease of 450 the concentrations of the following steroids was observed DHEA-S ( $p<0.002)$, DHEA ( $<<$ $0.03)$, estradiol ( $\mathrm{p}<0.02)$, and estrone $(\mathrm{p}<0.02)$. Although our study measures 
concentrations of steroids in cattle and this study measured steroid in humans, it confirms that there is down regulation of estradiol-17ß-glucuronide and estrone-3-glucuronide after treatment with clenbuterol. Until now, there is no conclusive explanation for the down

455 regulating effects of beta-agonist on estradiol-17ß-glucuronide and estrone-3-glucuronide concentrations.

\subsubsection{Diethylstilbestrol administration}

In the past DES has been used on a large scale in animal fattening. It was found to be very

460 effective. In view of its potential impact on food safety, it remains a compound to be monitored. In this study an animal was treated with DES. The concentration of DES increases rapidly after injection and drops also very fast but remains detectable during the whole treatment period and at least one weak afterwards ( see supplementary data for the excretion curve of DES). After evaluating the S-plot it was determined that only estradiol-

465 17 $\beta$-glucuronide differs before and after treatment. In the Box-Whisker plot (figure 4C) an increase of estradiol-17 $\beta$-glucuronide can be observed after the second treatment when compared to non-treated animals from the same animal experiment. After treatment the average concentration of Estradiol-glucuronide increases slowly with the highest concentrations after 2 weeks. The increase in average concentration is almost a factor 2 470 compared to the concentrations before treatment.

DES is classified as a nonsteroidal estrogen. In literature the effect of DES is described as feminization of males linking this to its estrogenic properties. It is known that DES has extreme strong estrogenic properties. It is therefore expected that the concentrations of natural estrogenic compounds would decrease during treatment, as can be seen from figure 4 
475 there is no decrease in estradiol-glucuronide. However, after the animal was injected for the last time with DES there is strong increase in the concentration of estradiol-glucuronide. This is probably caused by a balancing reaction of the body to the declined concentrations of DES after the last ingestion of DES. An explanation of this observation could be that the animal compensates for the decrease in estrogens by increasing the natural production of estrogens 480 (overshoot) as clearly can be seen in figure 4 after 2 weeks of treatment. 

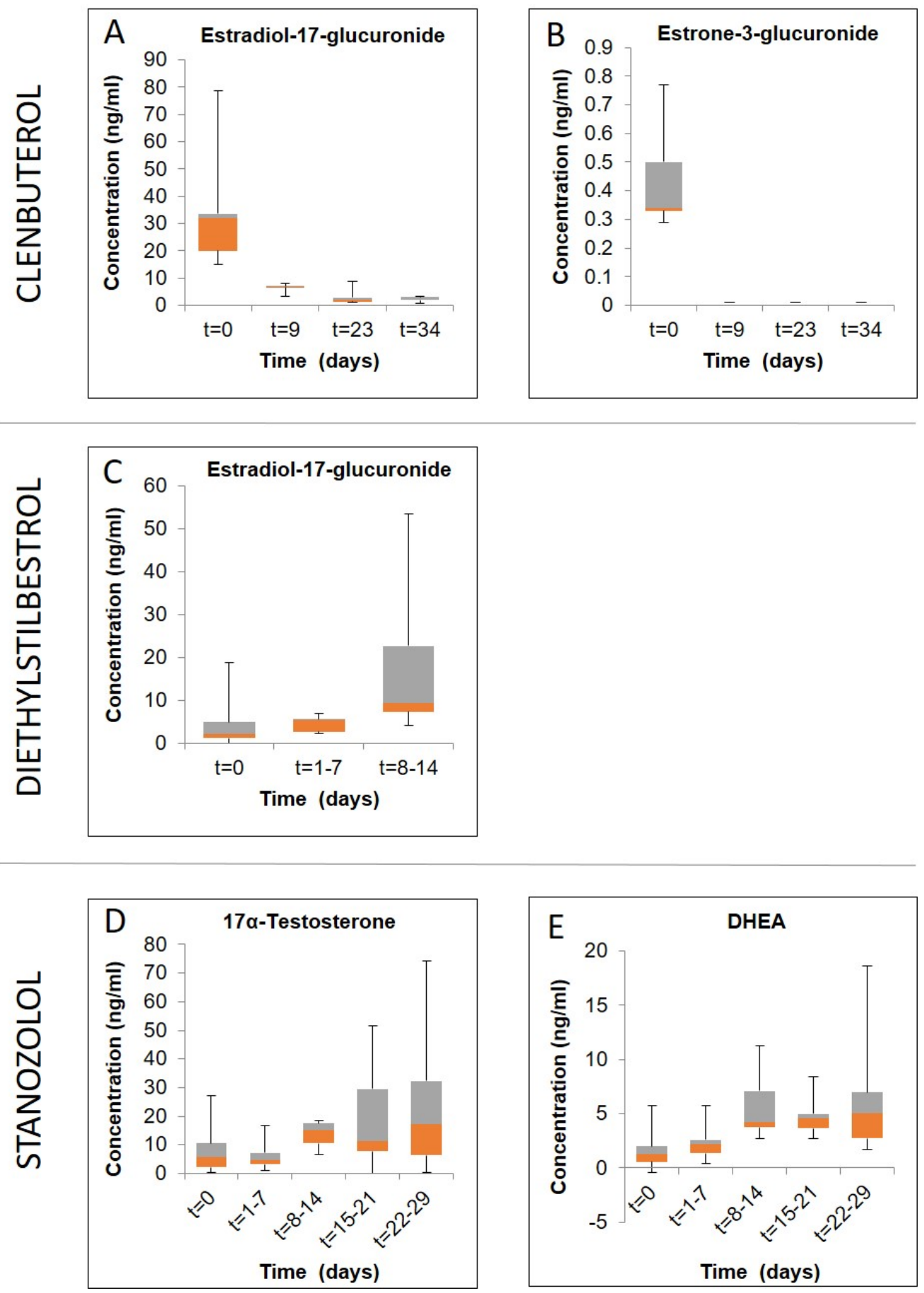

Figure 4: Box-Whisker plots shows concentration levels ( $t=0$ is before treatment, other days treatment period); the box limits are in the 25th and 75th percentiles, and the band in the middle of the box is the median; the whiskers are the absolute maximum and minimum concentrations measured. A) Concentration of estradiol-17 $\beta$-glucuronide before and after clenbuterol treatment. B) Concentration of Estrone-3-glucuronide before and after clenbuterol treatment. C) Estradiol-17 $\beta$ glucuronide before and during DES treatment. D) $17 \alpha$-testosterone before and during stanozolol treatment. E) DHEA before and during stanozolol treatment. 
No effect of the DES treatment was observed on the levels of the androgens. This was contrary to a study in which there was a very small increase in the concentration of testosterone [38]. Since the observations are derived from only one animal treated with DES, more animal studies must be performed to confirm the observed results.

500

\subsubsection{Stanozolol treatment}

This compound has strong anabolic effects and is found to be very effective in animals. In this study several animals were treated with stanozolol. The major metabolite after treatment of stanozolol in cattle is 16ß-hydroxystanozolol, the concentration of both compounds

505 remained stable during treatment (see supplementary data).

After examination of the S-plot it was found that several compounds were up-regulated after treatment. The compounds which were affected were $17 \alpha$-testosterone and DHEA. Both these compounds are closely connected in the androgen pathway. To assess the up regulation a Box-Whisker plot was made for both compounds (figure $4 \mathrm{D}$ and $\mathrm{E}$ ).

510 In general it is assumed that the natural androgen production declines after administration of a synthetic androgen $[1,22]$. The results in this study suggest otherwise. An explanation for the observed increase of testosterone and DHEA in urine could lie in the fact that stanozolol treatment decreases the natural circulating amount of sex hormone binding globuline (SHBG) after treatment. In humans the percentage of SHBG decreases by 50 percent after

515 one week of treatment $[39,40]$. As a result of this the amount of circulating free testosterone (there is no data on DHEA available) increases in blood. A higher circulating amount of free testosterone can result in higher excretion of testosterone in urine. As can be observed from figure 4 the amount of free $17 \alpha$-testosterone and DHEA starts to increase after the second 
treatment which would be in line with decreasing levels of circulating SHBG after one week 520 of treatment.

\subsection{Predictive model}

From the animal experiments with exogenous compounds it was observed that there is an effect on the amount of steroids circulating during or after treatment. In other words, the

525 treated animal tries to balance the steroid levels under influence of exogenous steroids. The type of balancing is probably typical for a specific treatment with exogenous growth promoters and related compounds and might be used to determine whether a treatment has occurred before sample collection. To detect these treatments, these changes in the steroid profile can be detected using a predictive multivariate model. This model is built using the

530 steroid profile of the different groups of treated animals. In this study a predictive model was build based on the clenbuterol, diethylstilbestrol and stanozolol. A blank population was included. Only a part of the blank population was used. The other blank samples were used to evaluate the model. To build the model the same approach was used as in previous sections. In figure 5 the visual representation of the OPLS-DA analysis of the three treated groups and 535 the blank group is shown. 
alle data.M14 (OPLS-DA), des-clen-stan-blanc

Scaled proportionally to R2X

Colored according to classes in M14

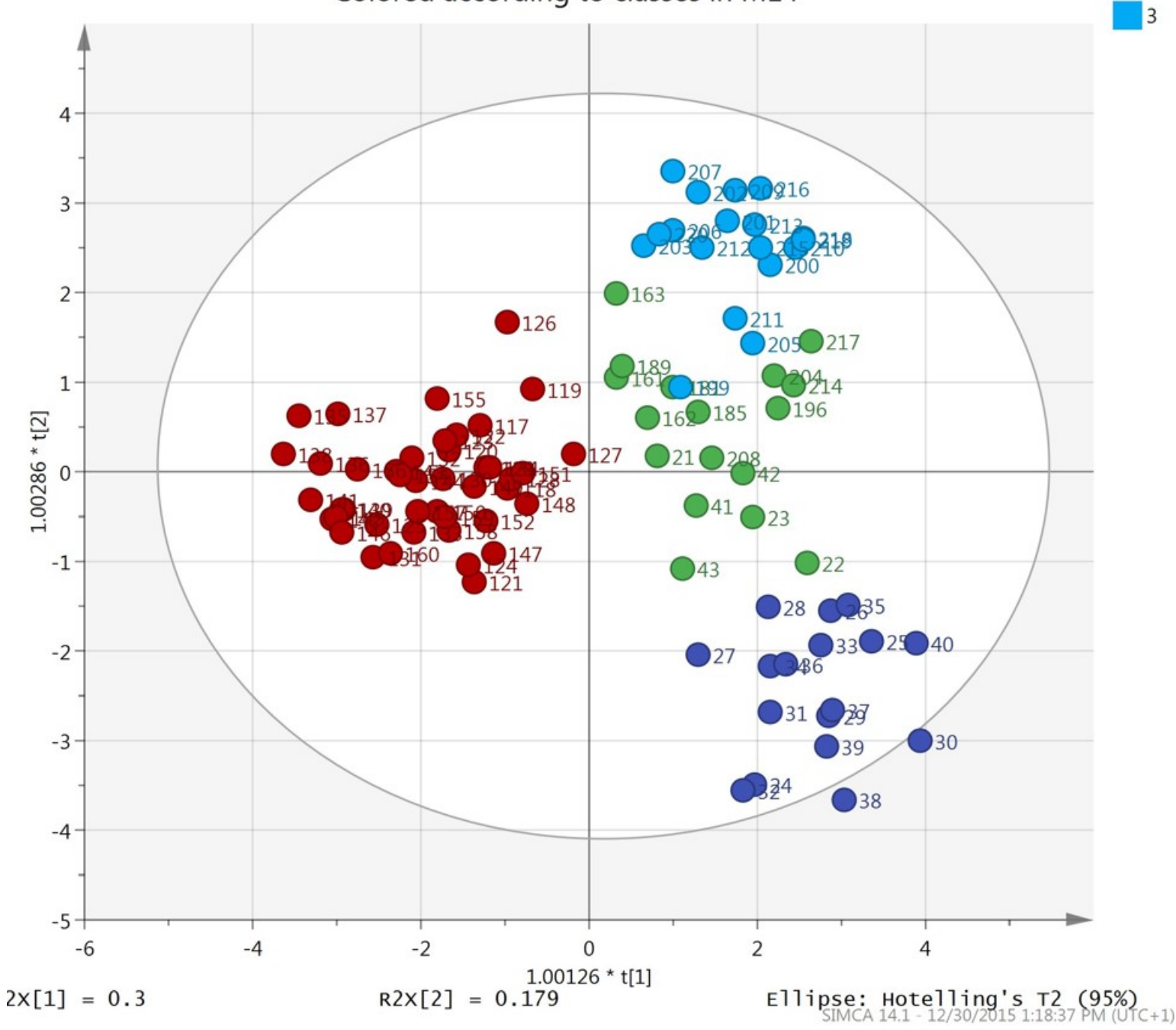

Figure 5. Visualisation of the OPLS-DA separation based on the steroid profiles measurements of the diethylstilbestrol (dark blue), stanozolol (red) and clenbuterol (light blue) and the blank (green)

\section{5 population.}

The three treated groups are clearly separated. The stanozolol treated group is separated in the horizontal direction from the diethylstilbestrol and clenbuterol groups. The clenbuterol and diethylstilbestrol groups are separated from each other in the vertical direction indicating that there is a difference but not as large as the one compared with stanozolol. This separation 
makes sense since the underlying effect on the steroidogenesis is different for each treatment. Stanozolol is mainly affecting the androgen synthesis and diethylstilbestrol and clenbuterol affect the estrogen synthesis. The blank population fits almost in the middle of the three treatments. Some of the blanks are projected in one of the treatments groups, this can be 555 expected since the effects of exogenous treatments are subtle. Also, a few weeks after treatment urine samples will have a normal steroid profile and will be classified in the blank population,

The samples used to build the predictive models originated from controlled animal experiments and therefore are from a homogenous group for which all factors are controlled.

560 Due to the fact that it is a homogenous group the variability between the animals will be relatively low. In real life samples will originate from different animals and have a higher variability . It is known that age and gender have an influence on steroid levels in urine samples and also race might influence the steroid profile. For example, Belgium Blues have low steroid levels compared to other races (unpublished data obtained at the author's

565 laboratory). Additionally, in adult females, progesterone and estrogen levels will vary throughout the oestrus cycle [41], adding even more variability. All of these factors imply that making a similar predictive model for other animals than (bull) calves, will be significantly more difficult. To evaluate the effect of a non-homogenous group on the model a large number $(\mathrm{n}=76)$ of samples of guaranteed non-treated animals was projected into the

570 model. These samples originated from different animal experiments conducted over the years by our laboratory and included animals of different age and sex.

It was found that from the projected blank samples $78 \%$ was classified as being a blank and the others were classified in one of the treated animals groups. In general a score of $95 \%$ is 
considered as acceptable for classification analysis to detect treatment. This results in a

575 screening result of maximum $5 \%$ false positive results. The lower score of $78 \%$ can be explained by the increased heterogeneity when compared to the reference set of mainly male animals. This means that the composition of the reference group should match that of the test group (routine samples in practice). This will ask careful study in the future, because broadening the composition of the reference group will inevitably decrease the

580 sensitivity of the model to detect deviations. Despite this score the model can be used as a first indication (screening), whether a sample has a steroids profile deviating from the profile that belongs to a reference population of untreated animals. In routine analyses, this evaluation can only be performed when a large number of samples is collected during routine control programs. By evaluating this large data set a reliable "normal” steroid profile of 585 animals can be defined.

\section{Conclusion}

A robust method was developed to quantify a large number of steroids and corresponding phase I and phase II metabolites in urine. The CC $\alpha$ for most compounds is lower than $1 \mathrm{ng}$ $590 \mathrm{ml}^{-1}$ with a measurement uncertainty lower than 30\%. The method was fully validated and was applied to assess the influence of exogenous growth promoters on the steroidogenesis. From the analysis of the treatment with clenbuterol it was concluded estradiol-17 $\beta$ glucuronide and estrone-3-glucuronide were down regulated. The mode of action of this effect is not known. Treatment with diethylstilbestrol, a strong estrogenic compound, 595 increases the excretion of natural estrogenic compounds in urine. The treatment with a strong 
androgenic compound, stanozolol, shows a similar effect on the upregulation of the androgenic excretion in urine.

This study has shown that the steroid profiling analysis of urine is a useful tool to identify and quantify changes in the steroidogenesis after treatment with growth promoters. The effect

600 of an estrogenic or androgenic treatment is visible after treatment and can be used in a generic control (effect based screening) strategy to determine if an animal belongs to a normal population or a treated population. A classification model where the steroid profiles before and after treatments are modelled using OPLS-DA, demonstrates that it is possible to identify animals that have been treated. Due to the limited number of animals and treatments

605 assessed in this study, more animals obtained from farms and from different treatment regimens have to be added in the future.

These results show that steroid profiling can be used as an additional approach to effect based screening. To further decrease the number of false positive results, the reference sets will need to be improved in order to, as precise as possible, match the test populations. As such, it

610 forms an important new approach for the untargeted analyses for hormonal active compounds. It opens the door to another type of detection of abuse of androgenic, estrogenic and beta-agonists compounds.

\section{ACKNOWLEDGMENT}

615 This project was financially supported by the Dutch Ministry of Economic Affairs and the European Commission (DG Santé) . We would like to thank Maria Groot from RIKILT Wageningen Research (the Netherlands), Irmgard Riedmaier from Technische Universität München (Germany) and Johan van den Hende from the of University of Ghent (Belgium) 
for performing the controlled animal treatment experiments and making the materials

620 available for this study.

\section{References}

[1] H. Kuipers, Anabolic steroids: Side Effects, Internet Society for Sport Science: http://sportsci.org. , 1998.

625 [2] A. Ruokonen, M. Alen, N. Bolton, R. Vihko, Response of serum testosterone and its precursor steroids, SHBG and CBG to anabolic steroid and testosterone selfadministration in man, J. Steroid Biochemistry 23(1) (1985) 33-38.

[3] World Anti Doping Agency. The 2016 Prohibited List. Downloaded from https://wada-main-prod.s3.amazonaws.com/resources/files/wada-2015-prohibited-list630 en.pdf [Accessed 21.03.2016].

[4] Council Directive 96/22/EC of 29 April 1996 concerning the prohibition on the use in stockfarming of certain substances having a hormonal or thyrostatic action and of $\beta$ agonists, and repealing Directives 81/602/EEC, 88/146/EEC and 88/299/EEC, Official Journal L 125 (1996) 3-9.

635 [5] Council Directive 2003/74/EC amending 96/22/EC concerning the prohibition on the use in stockfarming of certain substances having a hormonal or thyrostatic action and of ß-agonist, Directive 2003/74/EC, Brussels, 2003.

[6] Directive 2008/97/EC of the European Parliament and of the Council of 19 November 2008 amending Council Directive 96/22/EC concerning the prohibition on the

640 use in stockfarming of certain substances having a hormonal or thyrostatic action and of beta-agonists.

[7] A.A. Stolker, U.A. Brinkman, Analytical strategies for residue analysis of veterinary drugs and growth-promoting agents in food-producing animals--a review, Journal of chromatography. A 1067(1-2) (2005) 15-53.

645 [8] O.J. Pozo, N. De Brabanter, A. Fabregat, J. Segura, R. Ventura, P. Van Eenoo, K. Deventer, Current status and bioanalytical challenges in the detection of unknown anabolic androgenic steroids in doping control analysis, Bioanalysis 5(21) (2013) 2661-2677.

[9] M.H. Blokland, H.J. van Rossum, S.S. Sterk, L.A. van Ginkel, R.W. Stephany, Development of a method which discriminates between endogenous and exogenous beta-

650 boldenone, Analytica Chimica Acta 586(1-2) (2007) 147-153. [10] R.L. Gomes, W. Meredith, C.E. Snape, M.A. Sephton, Conjugated steroids: analytical approaches and applications, Analytical and bioanalytical chemistry 393(2) (2009) 453-458.

[11] T.F.H. Bovee, H.H. Heskamp, A.R.M. Hamers, R.L.A.P. Hoogenboom, M.W.F.

655 Nielen, Validation of a rapid yeast estrogen bioassay, based on the expression of green fluorescent protein, for the screening of estrogenic activity in calf urine, Analytica Chimica Acta 529(1-2) (2005) 57-64.

[12] L.A. van Ginkel, S.S. Sterk, A view on the analytical design of future risk based residue control, Drug testing and analysis 8(5-6) (2016) 521-524. 
660 [13] S. Anizan, D. Di Nardo, E. Bichon, F. Monteau, N. Cesbron, J.P. Antignac, B. Le Bizec, Targeted phase II metabolites profiling as new screening strategy to investigate natural steroid abuse in animal breeding, Anal Chim Acta 700(1-2) (2011) 105-113. [14] M.H. Blokland, E.F. Van Tricht, H.J. Van Rossum, S.S. Sterk, M.W. Nielen, Endogenous steroid profiling by gas chromatography-tandem mass spectrometry and

665 multivariate statistics for the detection of natural hormone abuse in cattle, Food additives \& contaminants. Part A, Chemistry, analysis, control, exposure \& risk assessment 29(7) (2012) 1030-1045.

[15] L.M. Bloem, K.H. Storbeck, P. Swart, T. du Toit, L. Schloms, A.C. Swart, Advances in the analytical methodologies: Profiling steroids in familiar pathways-

670 challenging dogmas, J Steroid Biochem Mol Biol 153 (2015) 80-92.

[16] G. Janssens, S. Mangelinckx, D. Courtheyn, S. Prevost, G. De Poorter, N. De Kimpe, B. Le Bizec, Application of gas chromatography-mass spectrometry/combustion/isotope ratio mass spectrometry (GC-MS/C/IRMS) to detect the abuse of 17beta-estradiol in cattle, J Agric Food Chem 61(30) (2013) 7242-7249.

675 [17] S. Prevost, T. Nicol, F. Monteau, F. Andre, B. Le Bizec, Gas chromatography/combustion/isotope ratio mass spectrometry to control the misuse of androgens in breeding animals: new derivatisation method applied to testosterone metabolites and precursors in urine samples, Rapid communications in mass spectrometry : RCM 15(24) (2001) 2509-2514.

680 [18] G. Janssens, S. Mangelinckx, D. Courtheyn, N. De Kimpe, B. Matthijs, B. Le Bizec, The use of gas chromatography-mass spectrometry/combustion/isotope ratio mass spectrometry to demonstrate progesterone treatment in bovines, Journal of Chromatography A 1449 (2016) 129-140.

[19] G. Janssens, D. Courtheyn, S. Mangelinckx, S. Prevost, E. Bichon, F. Monteau, G.

685 De Poorter, N. De Kimpe, B. Le Bizec, Use of isotope ratio mass spectrometry to differentiate between endogenous steroids and synthetic homologues in cattle: A review, Analytica Chimica Acta 772 (2013) 1-15.

[20] F.C.W. Wu, 7 Testicular steroidogenesis and androgen use and abuse, Baillière's Clinical Endocrinology and Metabolism 6(2) (1992) 373-403.

690 [21] A.T. Kicman, Pharmacology of anabolic steroids, British journal of pharmacology 154(3) (2008) 502-521.

[22] J. van Amsterdam, A. Opperhuizen, F. Hartgens, Adverse health effects of anabolic-androgenic steroids, Regul Toxicol Pharmacol 57(1) (2010) 117-123.

[23] I. Athanasiadou, Y.S. Angelis, E. Lyris, C. Georgakopoulos, Chemical

695 derivatization to enhance ionization of anabolic steroids in LC-MS for doping-control analysis, Trac-Trend Anal Chem 42 (2013) 137-156.

[24] K. Yamashita, M. Okuyama, Y. Watanabe, S. Honma, S. Kobayashi, M. Numazawa, Highly sensitive determination of estrone and estradiol in human serum by liquid chromatography-electrospray ionization tandem mass spectrometry, Steroids 72(11-

700 12) (2007) 819-827.

[25] A. Raun, R. Preston, History of diethylstilbestrol use in cattle, J Anim Sci (2002).

[26] I. Riedmaier, M. Spornraft, M.W. Pfaffl, Identification of a potential gene expression biomarker signature in bovine liver to detect the abuse of growth promoters, Food additives \& contaminants. Part A, Chemistry, analysis, control, exposure \& risk

705 assessment 31(4) (2014) 641-649. 
[27] K. Vanoosthuyze, E. Daeseleire, A. Vanoverbeke, C. Vanpeteghem, A. Ermens, Survey of the Hormones Used in Cattle Fattening Based on the Analysis of Belgian Injection Sites, Analyst 119(12) (1994) 2655-2658.

[28] H.J. Weeth, R. Witton, C.F. Speth, Prediction of Bovine Urine Specific Gravity and

710 Total Solids by Refractometry, Journal of Animal Science 28(1) (1969) 66-\&.

[29] B. Worley, R. Powers, Multivariate Analysis in Metabolomics, Curr Metabolomics 1(1) (2013) 92-107.

[30] C.D. 2002/657/EC, Council Decision 2002/657/EC, Off. J. Eur. Communities 221 (2002) 8.

715 [31] N. ISO, 11843-2 (2000) Capability of detection, Part 2: Methodology in the linear calibration case, Standard, NF ISO (2000) 11843-11842.

[32] I. Standard, 5725-2 (1994), 5725-2 (1994) Accuracy (trueness and precision) of measurement methods and results-Part 2: Basic method for the determination of repeatability and reproducibility of a standard measurement method, International

720 Organization for Standardization (ISO) Geneva, Switzerland.

[33] S.E. Jantti, M. Hartonen, M. Hilvo, H. Nygren, T. Hyotylainen, R.A. Ketola, R. Kostiainen, Steroid and steroid glucuronide profiles in urine during pregnancy determined by liquid chromatography-electrospray ionization-tandem mass spectrometry, Anal Chim Acta 802 (2013) 56-66.

725 [34] S.E. Jantti, A. Tammimaki, H. Raattamaa, P. Piepponen, R. Kostiainen, R.A. Ketola, Determination of steroids and their intact glucuronide conjugates in mouse brain by capillary liquid chromatography-tandem mass spectrometry, Analytical chemistry 82(8) (2010) 3168-3175.

[35] N. Maeda, E. Tanaka, T. Suzuki, K. Okumura, S. Nomura, T. Miyasho, S. Haeno,

730 H. Yokota, Accurate determination of tissue steroid hormones, precursors and conjugates in adult male rat, Journal of biochemistry 153(1) (2013) 63-71.

[36] A.M. Flores-Valverde, E.M. Hill, Methodology for profiling the steroid metabolome in animal tissues using ultraperformance liquid chromatography-electrospraytime-of-flight mass spectrometry, Analytical chemistry 80(22) (2008) 8771-8779.

735 [37] M.N. Triba, L. Le Moyec, R. Amathieu, C. Goossens, N. Bouchemal, P. Nahon, D.N. Rutledge, P. Savarin, PLS/OPLS models in metabolomics: the impact of permutation of dataset rows on the K-fold cross-validation quality parameters, Mol Biosyst 11(1) (2015) 13-19.

[38] T.G. Martin, R.E. Erb, W.L. Singleton, F.H. Owens, Comparison of four levels of

740 protein supplementation with and without oral DES on reproductive traits and testosterone of bulls, J Anim Sci 48(5) (1979) 1033-1039.

[39] G. Sinnecker, S. Kohler, Sex hormone-binding globulin response to the anabolic steroid stanozolol: evidence for its suitability as a biological androgen sensitivity test, The Journal of clinical endocrinology and metabolism 68(6) (1989) 1195-1200.

745 [40] G. Sinnecker, S. Köhler, A new biological androgen sensitivity test: the sex hormone binding globulin (SHBG)-response to the anabolic steroid stanozolol, Acta Endocrinologica 117(4 Suppl) (1988) S215-S216.

[41] H. Garverick, R. Erb, G. Niswender, C. Callahan, Reproductive steroids in the bovine. III. Changes during the estrous cycle, Journal of animal science 32(5) (1971) 946750956. 